\title{
Increase of Rutin, Quercetin, and Antioxidant Activity during Germinated Buckwheat (Fagopyrum esculentum Moench) Fermentation
}

\section{Pov Ratha and Deok-Young Jhon*}

Department of Food and Nutrition, Chonnam National University, Yongbong-ro, Buk-gu, Gwangju, 61186, Republic of Korea

*Corresponding author: Deok-Young Jhon, Department of Food and Nutrition, Chonnam National University, Yongbong-ro, Buk-gu, Gwangju, 61186, Republic of Korea, Tel: +82625301335; E-mail: dyjhon@gmail.com

Received date: October 15, 2017; Accepted date: October 23, 2017; Published date: October 29, 2017

Copyright: $@ 2017$ Ratha et al. This is an open-access article distributed under the terms of the Creative Commons Attribution License, which permits unrestricted use, distribution, and reproduction in any medium, provided the original author and source are credited.

\begin{abstract}
Buckwheat is gaining increasing attention as a potential functional food due to its content of bioactive compounds such as rutin, quercetin and other antioxidant substances. In this paper changes in content of rutin, quercetin and antioxidant activity in buckwheat have been measured during germination and fermentation. Buckwheat seeds were germinated for 2 days at $18^{\circ} \mathrm{C}$ and dried for $20 \mathrm{~h}$ at $60^{\circ} \mathrm{C}$. Fermentation was carried out at $30^{\circ} \mathrm{C}$ for Bif. breve BV-B and Bac. subtilis, $37^{\circ} \mathrm{C}$ for Lactobacillus spp. and Bif. animalis, and $40^{\circ} \mathrm{C}$ for Bacillus sp. $224 \mathrm{~B} 4$ and Bac. subtilis B53 for 48-72 $\mathrm{h}$. When the buckwheat was germinated, the content of rutin decreased from $0.17 \mathrm{~g} \mathrm{~kg}^{-1}$ to $0.1 \mathrm{~g} \mathrm{~kg}^{-1}$ and did not show the effect on increasing the content of quercetin during germination $\left(0.18-0.19 \mathrm{~g} \mathrm{~kg}^{-1}\right)$. However, when the germinated buckwheat was fermented with Bifidobacterium breve BV-B, Bacillus subtilis B53, and Lactobacillus buchneri, the contents of rutin and quercetin increased to $0.97 \mathrm{~g} \mathrm{~kg}^{-1}$ and $2.53 \mathrm{~g} \mathrm{~kg}^{-1}, 0.56 \mathrm{~g} \mathrm{~kg}^{-1}$ and $0.13 \mathrm{~g} \mathrm{~kg}^{-1}, 0.37 \mathrm{~g} \mathrm{~kg}^{-1}$ and $0.16 \mathrm{~g} \mathrm{~kg}^{-1}$, respectively. The antioxidant activities such as total phenolic compounds, total flavonoid content, DPPH radical scavenging activity and ABTS radical scavenging activity of fermented buckwheat were $3.41 \%, 4.28 \%, 65.21 \%$ and $45.46 \%$, respectively, when Lac. buchneri microorganism was used. Lac. plantarum, Bif. animalis, and Bif. breve BV-B showed active fermentation. Overall acceptability of germinated buckwheat fermented by Bacillus sp. 224 B4, Bac. subtilis B53, Bac. subtilis KCCM11315, Bif. animalis, and Bif. breve BV-B was evaluated as good or very good. This study shows that germinated buckwheat fermented with Lac. buchneri, Lac. plantarum, Bif. animalis and Bif. breve BV-B, respectively, is promising as a health functional food.
\end{abstract}

Keywords: Buckwheat; Germinated; Fermentation; Rutin; Quercetin; Antioxidant activity

\section{Introduction}

Buckwheat (Fagopyrum esculentum Moench) is a crop belonging to the Polygonaceae family and has been cultivated in many countries in Europe, Asia, South Africa, Canada and USA [1-3]. This plant is a rich source of vitamins, large quantity of phenolic compounds and has high protein content with a well-balanced amino acid composition $[2,4,5]$. In recent years because buckwheat has been perceived as a health promoting grain, it has become a highly appreciated ingredient for the preparation of functional foods [6]. In particular, an important source of rutin and quercetin also were detected in buckwheat grain [7]. Rutin is known to have beneficial health effects such as anti-inflammatory, anti-carcinogenic, cardiovascular benefits, reduced blood pressure, lowered blood sugar concentration, and increased antioxidant activity $[8,9]$. Quercetin has benefic such as antioxidant, anti-inflammatory, anti-bacterial, anti-coagulative, and anti-hypertensive properties [10-13].

Germination methods are also used to improve the nutritional quality of cereals. It has been reported that the antioxidant activity of germinated barley is higher than that of non-germinated barley [14]. In germinated brown rice, it has been reported that there is 10 times more $\gamma$-aminobutyric acid, which has an antihypertensive effect, as compared to non-germinated brown rice [15]. During the past few years, research has been conducted on the change of flavonoids and antioxidant activities of germinated buckwheat seeds. The highest rutin content in germinated buckwheat was found to be $0.158 \mathrm{~g} \mathrm{~kg}^{-1}$ [16].
Germinated buckwheat had better nutritional value and antioxidant activities than non-germinated buckwheat, and it represented an excellent natural source of flavonoids and phenolic compounds, especially rutin and C-glycosylflavones [17].

Various fermented cereal products, such as foods containing probiotic bacteria, rice vinegar, soy sauce, soybean-barley paste, natto and tempeh, are sold in food stores in Asia [18]. New bioactive metabolites in cereals can be produced during fermentation from the starters present in raw materials. Modification of the cereal matrix during fermentation can be tailored to increase the bioaccessibility of bioactive compounds [19]. The fermentation by selected LAB strains can strongly increase the functional benefits of buckwheat by releasing the functional $\gamma$-aminobutyric acid in the sourdough [20]. However, there is no article that mentions the increase of rutin and quercetin in fermented buckwheat. This study was performed to determine the antioxidant activity, rutin, and quercetin after fermentation of nongerminated and germinated buckwheat using Bacillus spp., Lactobacillus spp., and Bifidobacterium spp.

\section{Materials and Methods}

\section{Microorganisms}

Bifidobacterium animalis DY-64 was isolated from human feces [21]. Bifidobacterium breve BV-B (KCCM43018), Lactobacillus plantarum (KCCM12116), Lactobacillus buchneri (KCCM40982), and Bacillus subtilis (KCCM11315) were purchased from the Korean Culture Center of Microorganism (KCCM). Bacillus sp.224 B4 and Bac. subtilis B53 (KCCM 11609P) were isolated from Chungkookjang 
in this laboratory. Bacillus spp. were cultivated in edible LB broth and Lactobacillus spp. and Bifidobacterium spp. were cultured in MRS broth.

\section{Germination conditions}

Buckwheat (Fagopyrum esculentum Moench) grain obtained from North Gwangju, South Korea. Buckwheat seeds were cleaned and soaked in water for $5 \mathrm{~h}$ at room temperature. The steeped seeds were drained off, spread out on wet gauze placed in baskets. Germination was carried out in the dark in a germination cabinet for 2 days at $18^{\circ} \mathrm{C}$. After germination buckwheat was dried for $20 \mathrm{~h}$ at $60^{\circ} \mathrm{C}$ and was stored at $4^{\circ} \mathrm{C}$ until its use.

\section{Fermentation conditions}

Buckwheats were autoclaved in same amount of water (w/v 1:1) at $121^{\circ} \mathrm{C}$ for $15 \mathrm{~min}$. After autoclaving, the samples were cooled to $40-50^{\circ} \mathrm{C}$ and Bacillus spp., Lactobacillus spp. and Bifidobacterium spp. starter culture were inoculated in $10 \%$ of the sample buckwheat weight. The fermentation temperature was $30^{\circ} \mathrm{C}$ for Bif. breve BV-B and Bac. subtilis, $37^{\circ} \mathrm{C}$ for Lactobacillus spp. and Bif. animalis, and $40^{\circ} \mathrm{C}$ for Bacillus sp. 224 B4 and Bac. subtilis B53 and incubate for $48-72 \mathrm{~h}$.

\section{Rutin and quercetin analysis}

Rutin and quercetin were analyzed based on the method of Yoo et al. [22]. Fermented non-germinated or germinated buckwheat was dried in $60^{\circ} \mathrm{C}$ oven for $12 \mathrm{~h}$ and pulverized using a grinder. Sample powder $1 \mathrm{~g}$ was extracted with $20 \mathrm{~mL}$ of methanol at $80^{\circ} \mathrm{C}$, cooled overnight at $4^{\circ} \mathrm{C}$, and filtered through No. 41 Whatman filter papers. After the extracts were filtered through $0.45 \mu \mathrm{m}$ syringe filters, the amounts of rutin and quercetin were quantitatively measured using HPLC (Shimadzu LC-20, Japan) with a UV detector and Capcell Pak C18 column (UG120 S-5, Shiseido Co., Ltd., Japan). The mobile phase for HPLC analysis was consisted of methanol/acetic acid (v/v 95:5) (solvent A) and water (Solvent B). A linear gradient of water was applied from $85 \%$ to $90 \%$ for $35 \mathrm{~min}$, followed by an increase to $100 \%$ in $15 \mathrm{~min}$ of (Solvent B). The flow rate was $0.5 \mathrm{~mL} / \mathrm{min}$, the column temperature was set at $45^{\circ} \mathrm{C}$, and the components were detected at 350 $\mathrm{nm}$.

\section{Determination of antioxidant activity}

Buckwheat flour extracts were prepared according to the method described by Prior et al. [23]. The buckwheat flour was treated with hexane (w/v 1:10, two successive $1 \mathrm{~h}$ extractions in the dark) to get rid of hydrophobic compounds. Then the residues extracted with hexane were sonicated and extracted twice with a mixture of acetone, water, and acetic acid (v/v/v 70:29.5:0.5) for $15 \mathrm{~min}(\mathrm{w} / \mathrm{v} \mathrm{1:20)}$. The extracts were combined, filtered and concentrated by a rotary evaporator. The obtained phenolic extracts were re-dissolved in methanol at the concentration of $1.0 \mathrm{mg} / \mathrm{mL}$ for the antioxidant activity and phenolic content analysis.

The phenolic content was measured using the Folin-Ciocalteu method. One $\mathrm{mL}$ of the sample was added to $9 \mathrm{~mL}$ of distilled water and vortexed. Then $1 \mathrm{~mL}$ of Folin-Cialteu reagent was added, vortexed and stood for $5 \mathrm{~min}$ at room temperature. $7 \mathrm{~mL}$ of $7 \%$ sodium carbonate and $4 \mathrm{~mL}$ distilled water were added, allowed to stand for 90 min at room temperature and absorbance was measured at $750 \mathrm{~nm}$ with a spectrophotometer. The flavonoid content was determined by a colorimetric method. Aliquots of extract $(1 \mathrm{~mL})$ were reacted with distilled water $(4 \mathrm{~mL})$ and $5 \%$ sodium nitrite $(0.3 \mathrm{~mL})$. After $5 \mathrm{~min}$, a $10 \%$ aluminum chloride solution $(0.3 \mathrm{~mL})$ and $1 \mathrm{M}$ sodium hydroxide $(2 \mathrm{~mL})$ were added and allowed to stand $5 \mathrm{~min}$, followed by adjusting the volume to $5 \mathrm{~mL}$ with distilled water. After $15 \mathrm{~min}$, the absorbance was measured at $510 \mathrm{~nm}$ with a spectrophotometer.

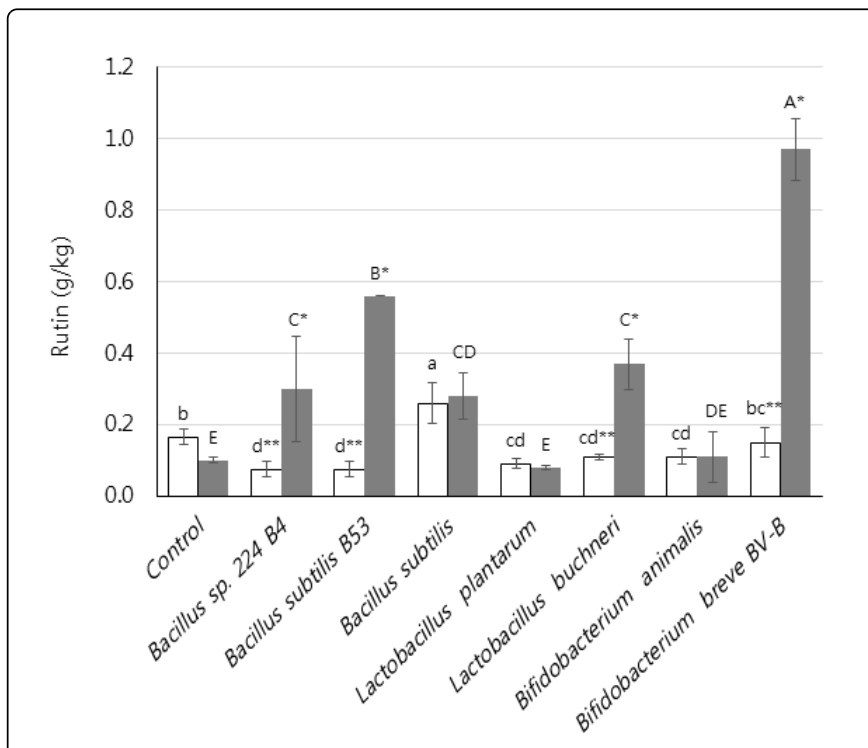

Figure 1: Rutin amount in non-germinated or germinated buckwheat fermented with different kind of microorganisms. Open bar indicates non-germinated and filled bar indicates germinated sample. For each set of samples, mean values of bars with different letters ( $a, b, c$ for non-germinated and A, B, C for germinated) are significantly different $(\mathrm{P}<0.05)$. ${ }^{*}$ indicate significant differences $(\mathrm{P}<0.05)$ in non-germinated and germinated buckwheat. Error bars represent for sample $n=3$.

A working solution of $0.1 \mathrm{mM}$ DPPH (2, 2-diphenyl-1picrylhydrazyl) was prepared in absolute ethanol. Before the assay, the absorbance of the working solution was read at $515 \mathrm{~nm} .380 \mu \mathrm{L}$ of the DPPH solution and $20 \mu \mathrm{L}$ of the sample were added to a 96 wall micro plate reader, with shaking for $5 \mathrm{~s}$, and allowed to stand for $30 \mathrm{~min}$ at room temperature. Absorbance was read at $515 \mathrm{~nm}$.

$$
\text { DPPH(\%) }=1-\frac{\text { absorbance of sample }}{\text { absorbance of control }} \times 100 \%
$$

ABTS stock was prepare by addition of $3 \mathrm{~mL}$ potassium phosphate buffer to $7 \mathrm{mM}$ ABTS $(0.012 \mathrm{~g} / 3 \mathrm{~mL}+2.45 \mathrm{mM}$ potassium persulfate $0.018 \mathrm{~g}$ ), vortexed and kept in the refrigerator for $12 \mathrm{~h}$. Stock solution was diluted 70 times to make working solution in water. Working solution (v/v 70:1) was prepared by addition of $500 \mu \mathrm{L}$ stock solution to $38 \mathrm{~mL}$ phosphate buffered saline and vortexed. $10 \mu \mathrm{L}$ of the sample and $390 \mu \mathrm{L}$ of the working solution of ABTS were added to a 96 wall microplate reader, allowed to stand for $2 \mathrm{~min}$ and the absorbance was read at $734 \mathrm{~nm}$.

$$
\text { ABTS }(\%)=1-\frac{\text { absorbance of sample }}{\text { absorbance of control }} \times 100 \%
$$


Citation: Ratha P, Jhon DY (2017) Increase of Rutin, Quercetin, and Antioxidant Activity during Germinated Buckwheat (Fagopyrum esculentum Moench) Fermentation. Ferment Technol 6: 147. doi:10.4172/2167-7972.1000147

Page 3 of 6

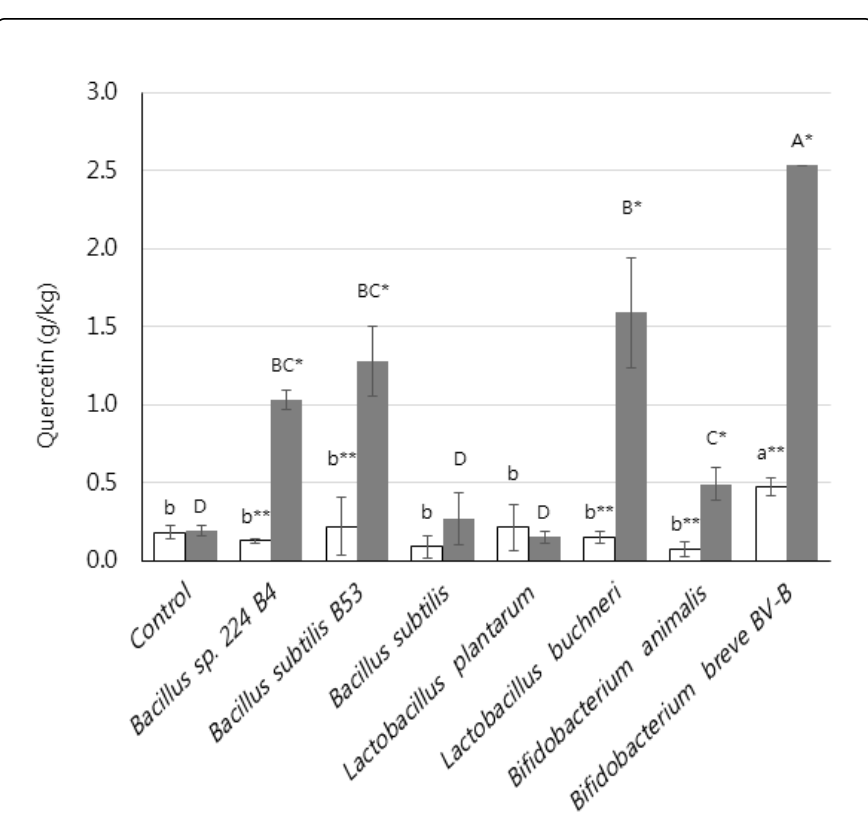

Figure 2: Quercetin amount in non-germinated or germinated buckwheat fermented with different kind of microorganisms. Open bar indicates non-germinated and filled bar indicates germinated sample. For each set of samples, mean values of bars with different letters ( $\mathrm{a}, \mathrm{b}, \mathrm{c}$ for non-germinated and $\mathrm{A}, \mathrm{B}, \mathrm{C}$ for germinated) are significantly different $(\mathrm{P}<0.05)$. *indicate significant differences $(\mathrm{P}<0.05)$ in non-germinated and germinated buckwheat. Error bars represent for sample $n=3$.

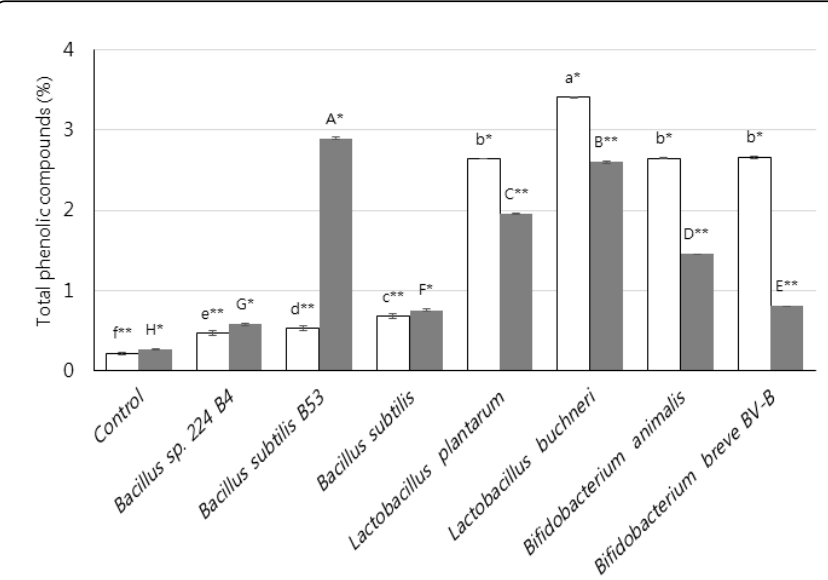

Figure 3: Total phenolic compounds in non-germinated or germinated buckwheat fermented with different kind of microorganisms. Open bar indicates non-germinated and filled bar indicates germinated sample. For each set of samples, mean values of bars with different letters ( $a, b, c$ for non-germinated and A, B, C for germinated) are significantly different $(\mathrm{P}<0.05)$. ${ }^{*}$ indicate significant differences $(\mathrm{P}<0.05)$ in non-germinated and germinated buckwheat. Error bars represent for sample $n=3$.

\section{Sensory evaluation}

Non-germinated and germinated fermented buckwheat samples, sensory evaluation was performed by student. Sensory evaluations of bitter taste, odor, savory taste and overall acceptability were performed using a 5 point scale. The scale level was consisted of "very strong" or "very good" (5 points), "strong" and "good" (4 points), "moderate" (3 points), "weak or poor" (2 points) and "very weak" or "very poor" (1 point).

\section{Statistical analysis}

All data were expressed as a mean \pm standard deviation. Duncan's multiple range test was used to test the difference between mean values of data. A p-value of $<0.05$ was considered statistically significant.

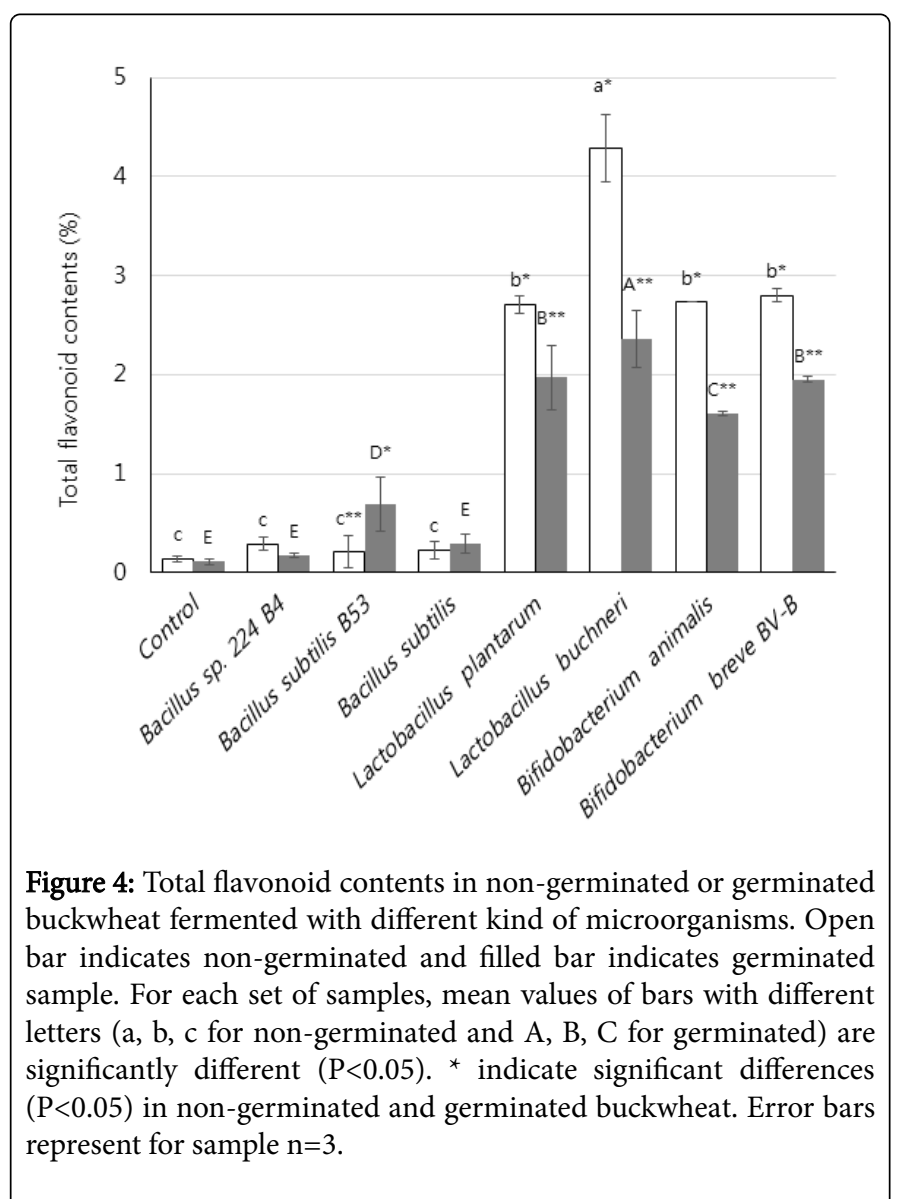

\section{Results and Discussion}

\section{Rutin and quercetin}

Rutin level in non-germinated buckwheat decreased to approximately $0.1 \mathrm{~g} / \mathrm{kg}$ following fermentation with Bacillus sp. 224 B4, Bac. subtilis B53, Lac. plantarum, Lac. buchneri, and Bif. animalis (Figure 1). Bif. breve BV-B fermentation of non-germinated buckwheat resulted in the same amount of rutin, and Bac. subtilis increased the level $\left(0.26 \mathrm{~g} \mathrm{~kg}^{-1}\right)$. Rutin amount was the same as the control $(0.17 \mathrm{~g}$ $\mathrm{kg}^{-1}$ ) in germinated buckwheat fermented with Lac. plantarum and Bif. animalis. The amounts increased to $0.3-0.97 \mathrm{~g} \mathrm{~kg}^{-1}$ by fermentation with Lac. buchneri, Bif. breve BV-B, Bacillus sp. 224 B4, Bac. subtilis 
B53, and Bac. subtilis. In addition, rutin amount in fermented germinated buckwheat was different from fermented non-germinated buckwheat as shown in Figure 1. Previous studies have reported a wide range of rutin content in common buckwheat. They were $0.2-0.3 \mathrm{~g} \mathrm{~kg}^{-1}$ [24] and $0.1 \mathrm{~g} \mathrm{~kg}^{-1}$ [25] in groats of buckwheat. Thus, these results are comparable to ours. However, our results showed that germinated buckwheat fermented by Lac. buchneri, Bif. breve BV-B, and Bac. subtilis $\mathrm{B} 53$ contained $0.37,0.97$, and $0.56 \mathrm{~g} / \mathrm{kg}$, respectively.

Quercetin concentration was $0.18-0.47 \mathrm{~g} \mathrm{~kg}^{-1}$ in buckwheat as shown in Figure 2. When buckwheat was fermented with Bac. subtilis or Bif. animalis the quercetin contents was similar to the control $(0.18$ $\left.\mathrm{g} \mathrm{kg}^{-1}\right)$. The fact of the matter is that there was no significant difference in quercetin content of non-germinated buckwheat control and the non-germinated buckwheat fermented with all the bacterial cultures used except Bif. breve BV-B. Quercetin amount in germinated and fermented buckwheat increased to $0.49-2.53 \mathrm{~g} \mathrm{~kg}^{-1}$, except the buckwheat fermented with Lac. plantarum or Bac. subtilis, that were not significantly different from the control $(0.19 \mathrm{~g} \mathrm{~kg}-1)$. Bif. breve BV$B$ produced the highest quercetin amount $\left(2.53 \mathrm{~g} \mathrm{~kg}^{-1}\right)$ by fermentation of germinated buckwheat.

In previous studies, the levels of quercetin were determined, and values of $0.3,1.2$, and $0.2 \mathrm{~g} \mathrm{~kg}^{-1}$ were reported for buckwheat hull, bran, and flour, respectively [26], with $4.3 \mathrm{~g} \mathrm{~kg}^{-1}$ for buckwheat noodle [22]. Thus, our results showed that either germinated or nongerminated buckwheat fermented with Bif. breve BV-B contain higher quercetin amount than those in buckwheats reported previously [26]. Figure 2 shows that quercetin amount in fermented non-germinated buckwheat was lower than fermented germinated buckwheat.

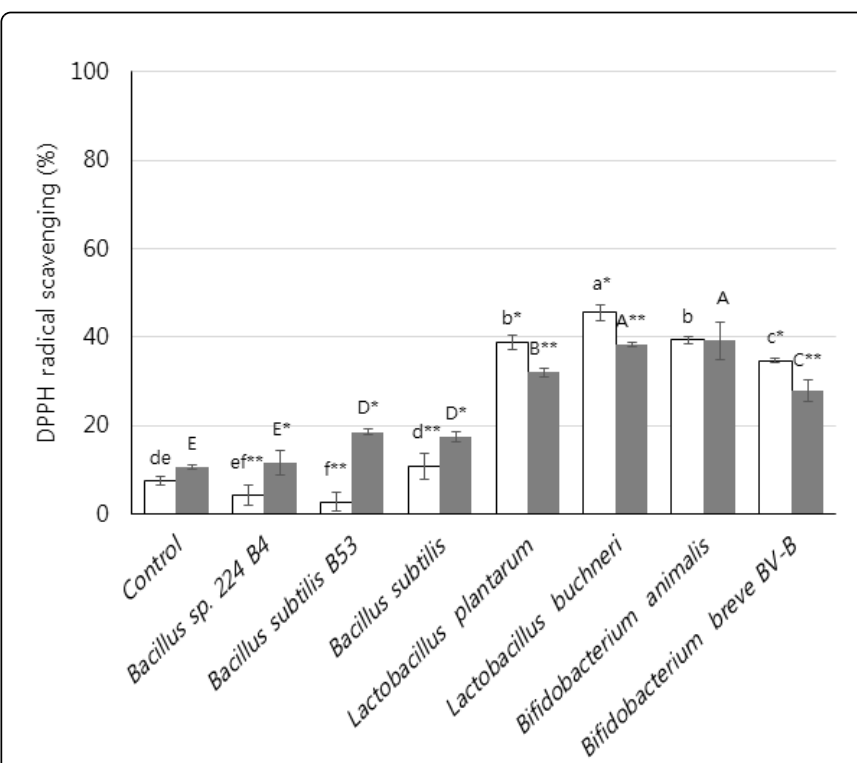

Figure 5: DPPH radical scavenging activity in non-germinated or germinated buckwheat fermented with different kind of microorganisms. Open bar indicates non-germinated and filled bar indicates germinated sample. For each set of samples, mean values of bars with different letters ( $a, b, c$ for non-germinated and A, B, C for germinated) are significantly different $(\mathrm{P}<0.05)$. *indicate significant differences $(\mathrm{P}<0.05)$ in non-germinated and germinated buckwheat. Error bars represent for sample $n=3$.

\section{Total phenolic compounds}

Total phenolic compounds of non-germinated buckwheat was $0.2 \%$. And the value was $0.27 \%$ in germinated buckwheat. When the nongerminated buckwheat was fermented with the starter microorganisms total phenolic compounds increased to $2.2-3.41 \%$. The amounts in non-germinated buckwheat fermented with Lac. buchneri, Bif. animalis, and Bif. breve BV-B was $3.41 \%, 2.65 \%$, and $2.66 \%$, respectively. The phenolic compounds in fermented germinated buckwheat were $0.27-2.9 \%$. The highest value of $2.9 \%$ was obtained from buckwheat fermented with Bac. subtilis B53. According to Chlopicka et al. [27], the total phenolic compounds in buckwheat was $0.73 \%$ in dry weight. Figure 3 shows that by the fermentation total phenolic compounds increased higher in non-germinated buckwheat than in germinated buckwheat.

\section{Total flavonoid content}

Total flavonoid contents of non-germinated buckwheat was $0.14 \%$ while the value of germinated buckwheat was $0.11 \%$. The range of total flavonoid contents in fermented non-germinated buckwheat was $0.14-4.28 \%$ and the highest value was found in products fermented with Lac. buchneri. Fermented germinated buckwheat contained 0.11-2.36\% flavonoids, with the highest value in buckwheat fermented with Lac. buchneri (2.36\%). Total flavonoid contents was reported previously as $0.015 \%$ in dry weight [27]. This value is lower than that obtained in this work. By the fermentation the total flavonoid contents increased higher in non-germinated buckwheat than in germinated buckwheat, as shown in Figure 4.

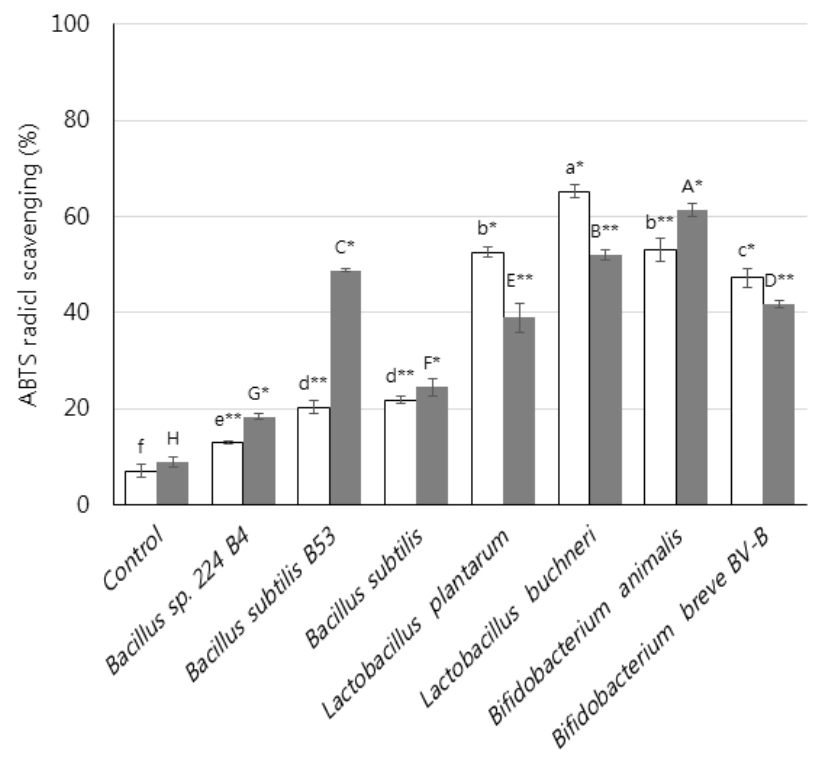

Figure 6: ABTS radical scavenging activity in non-germinated or germinated buckwheat fermented with different kind of microorganisms. Open bar indicates non-germinated and filled bar indicates germinated sample. For each set of samples, mean values of bars with different letters ( $a, b, c$ for non-germinated and A, B, C for germinated) are significantly different $(\mathrm{P}<0.05)$. *indicate significant differences $(\mathrm{P}<0.05)$ in non-germinated and germinated buckwheat. Error bars represent for sample $n=3$. 
Citation: Ratha P, Jhon DY (2017) Increase of Rutin, Quercetin, and Antioxidant Activity during Germinated Buckwheat (Fagopyrum esculentum Moench) Fermentation. Ferment Technol 6: 147. doi:10.4172/2167-7972.1000147

Page 5 of 6

\section{DPPH radical scavenging activity}

DPPH radical scavenging activity of non-germinated buckwheat was $7.75 \%$ while the value of germinated buckwheat was $10.73 \%$. The range of DPPH radical scavenging activity was $7.75-45.56 \%$ in fermented non-germinated buckwheat. Germinated buckwheat fermented with some edible bacteria showed 10.73-39.19\% DPPH radical scavenging activity. The amount in buckwheat fermented with Lac. buchneri, Bif. animalis, Lac. plantarum, and Bif. breve BV-B was $45.56 \%, 39.42 \%, 38.97 \%$ and $34.75 \%$, respectively. For the germinated buckwheat the higher DPPH radical scavenging activity was obtained by fermentation with Lac. buchneri, Bif. animalis, and Lac. plantarum and the value was $38.48 \%, 39.19 \%$, and $38.97 \%$, respectively. Sun and Ho reported buckwheat DPPH radical scavenging activity as $78.6 \%$ [28]. This value is higher than that obtained in this work. Fermentation increased DPPH radical scavenging activity compared to the control (7.45-10.73\%) as shown in Figure 5. The activity was heavily dependent on the starter microorganisms such as Lac. buchneri, Bif. animalis, and Lac. plantarum.

\section{ABTS radical scavenging activity}

ABTS radical scavenging activity of non-germinated buckwheat was $7.1 \%$ while the value of germinated buckwheat was $8.83 \%$. ABTS radical scavenging activity was $7.1-65.21 \%$ in fermented nongerminated buckwheat. The ABTS radical scavenging activity in fermented non-germinated buckwheat with Lac. buchneri, Bif. animalis, Lac. plantarum and Bif. breve BV-B was $65.21 \%, 53.14 \%$, $52.56 \%$ and $47.25 \%$, respectively. In germinated buckwheat fermented with some edible bacteria showed 8.83-61.41\% ABTS scavenging activity. The germinated fermented buckwheat the higher amount was obtained by Bif. animalis, Lac. buchneri, Lac. plantarum, Bac. subtilis B53, and Bif. breve BV-B and the value was $61.41 \%, 52.04 \%, 38.97 \%$, $48.84 \%$ and $41.78 \%$, respectively. Fermentation increased ABTS radical scavenging activity of non-germinated and germinated fermented buckwheat compared to the control (7.1-8.83\%) as shown in Figure 6.

\begin{tabular}{|c|c|c|c|c|c|c|}
\hline Microorganisms & $\begin{array}{l}\text { Buckwheat } \quad \text { (B) and } \\
\text { Germinated Buckwheat (GB) }\end{array}$ & ${ }^{\text {aBitter taste }}$ & aSour taste & aSavory taste & bodor & boverall acceptability \\
\hline \multirow[t]{2}{*}{ Bacillus sp.224 B4 } & B & 1 & - & 4.5 & 4.5 & 4.5 \\
\hline & GB & 1 & - & 4.5 & 3.5 & 4.5 \\
\hline \multirow{2}{*}{$\begin{array}{l}\text { Bacillus subtilis B53 } \\
\text { (KCCM 11609P) }\end{array}$} & B & 1 & - & 3 & 2 & 4 \\
\hline & GB & 1 & - & 3 & 1.5 & 4 \\
\hline \multirow{2}{*}{$\begin{array}{l}\text { Bacillus subtilis } \\
\text { (KCCM11315) }\end{array}$} & B & 1 & - & 4.5 & 3.5 & 4.5 \\
\hline & GB & 1.25 & - & 4 & 4 & 4 \\
\hline \multirow{2}{*}{$\begin{array}{l}\text { Bifidobacterium animalis } \\
\text { DY-64 }\end{array}$} & B & - & 3 & 3.5 & 4 & 3.8 \\
\hline & GB & - & 3.4 & 3.6 & 4.5 & 4.5 \\
\hline \multirow{2}{*}{$\begin{array}{l}\text { Bifidobacterium breve BV-B } \\
\text { (KCCM43018) }\end{array}$} & B & - & 3.25 & 2.75 & 3 & 3.1 \\
\hline & GB & - & 1.8 & 4 & 4.5 & 4 \\
\hline \multirow{2}{*}{$\begin{array}{l}\text { Lactobacillus plantarum } \\
\text { (KCCM12116) }\end{array}$} & B & - & 3.5 & 3 & 3 & 3.0 \\
\hline & GB & - & 3 & 2 & 3 & 3 \\
\hline \multirow{2}{*}{$\begin{array}{l}\text { Lactobacillus buchneri } \\
\text { (KCCM40982) }\end{array}$} & B & - & 3 & 3 & 3.5 & 3 \\
\hline & GB & - & 3 & 3 & 3.5 & 3.0 \\
\hline
\end{tabular}

Table 1: Sensory evaluation of fermented buckwheat.

\section{Sensory scores of fermented buckwheats}

The result of sensory evaluation by Bacillus spp., Lactobacillus spp., and Bifidobacterium spp. in buckwheat fermentation was show in Table 1 . The savory taste level of fermented non-germinated buckwheat and germinated fermented buckwheat by Bacillus sp. 224 B4 or Bac. subtilis KCCM11315 was higher than the score of Bif. animalis, Lac. buchneri, Lac. plantarum, and Bac. subtilis B53. The savory taste of geminated buckwheat fermented by Bif. breve BV-B was evaluated better than non-germinated one. All the products was not evaluated below level "moderate" in overall acceptability. The high score over 4 in overall acceptability was obtained in fermented buckwheat, whether it was germinated or not, by Bacillus sp. 224 B4, Bac. subtilis B53, and Bac. subtilis KCCM11315. By the way, only germinated buckwheat was evaluated as good or very good when it was fermented by Bif. animalis or Bif. breve BV-B.

\section{Conclusion}

This study demonstrates that fermented buckwheat exhibit significant amount of rutin, quercetin, and high antioxidant activities based on studies of total phenol contents, total flavonoid contents, $\mathrm{DPPH}$ radical scavenging activities, and ABTS radical scavenging activities. These findings suggest that fermented buckwheat based 
foods may contain important antioxidants that could be beneficial to human health. Fermentation processes can enhance the levels of many bioactive compounds in cereals and can be used to improve functional food. The type of fermentation clearly had an effect on the potentially bioactive constituents of buckwheat. However, studies on microbial population changes and activities of relevant enzymes during fermentation of cereals are required in order to establish the precise mechanisms that cause fermented cereals to improve their nutritional value. In this study, we found that high level of rutin and quercetin were present in fermented germinated buckwheat compared to the control. In particular, rutin and quercetin in germinated buckwheat fermented with Bif. breve BV-B, Bac. subtilis B53, Lac. buchneri contain 0.97 and 2.53, 0.56 and 0.13 , and $0.37 \mathrm{~g} \mathrm{~kg}^{-1}$ rutin and $0.16 \mathrm{~g}$ $\mathrm{kg}^{-1}$ quercetin, respectively. For antioxidant activity such as total phenol content, total flavonoid content, DPPH, and ABTS radical scavenging activities, the fermented buckwheat had higher values than the germinated buckwheat fermented with Lac. buchneri, with values of $3.41 \%, 4.28 \%, 65.21 \%$ and $45.46 \%$, respectively. Sensory score of germinated buckwheat fermented by Bacillus sp. 224 B4, Bac. subtilis B53, Bac. subtilis KCCM11315, Bif. animalis, and Bif. breve BV-B was very high.

\section{References}

1. Giménez-Bastida JA, Zieliński H (2015) Buckwheat as a Functional Food and Its Effects on Health. J Agric Food Chem 63: 7896-7913.

2. Kiprovski B, Mikulic-Petkovsek M, Slatnar A, Veberic R, Stampar F, et al. (2015) Comparison of phenolic profiles and antioxidant properties of European Fagopyrum esculentum cultivars. Food Chem 185: 41-47.

3. Wu X, Ge X, Liang S, Lv Y, Sun H (2015) A novel selective accelerated solvent extraction for effective separation and rapid simultaneous determination of six anthraquinones in tartary buckwheat and its products by UPLC-DAD. Food Analytical Methods 8: 1124-1132.

4. Sakac M, Torbica A, Sedej I, Hadnadev M (2011) Influence of breadmaking on antioxidant capacity of gluten free breads based on rice and buckwheat flours. Food Res Int 44: 2806-2813.

5. Mota C, Santos M, Mauro R, Samman N, Matos AS, et al. (2016) Protein content and amino acids profile of pseudocereals. Food Chem 193: 55-61.

6. Gao J, Kreft I, Chao G, Wang Y, Liu X, et al. (2016) Tartary buckwheat (Fagopyrum tataricum Gaertn.) starch, a side product in functional food production, as a potential source of retrograded starch. Food Chem 190: 552-558.

7. Sedej I, Sakac M, Mandic A, Mišan A, Tumbas V, et al. (2012) Buckwheat (Fagopyrum esculentum Moench) grain and fractions: antioxidant compounds and activities. J Food Sci 77: C954-C959.

8. Zhang Z-L, Zhou M-L, Tang Y, Li F-L, Tang Y-X, et al. (2012) Bioactive compounds in functional buckwheat food. Food Re Int 49:389-395.

9. Bai CZ, Feng ML, Hao XL, Zhong QM, Tong LG, et al. (2015) Rutin, quercetin, and free amino acid analysis in buckwheat (Fagopyrum) seeds from different locations. Genet Mol Res 14: 19040-19048.

10. Duarte J, Perez-Palencia R, Vargas F, Ocete MA, Perez-Vizcaino F, et al. (2001) Antihypertensive effects of the flavonoid quercetin in spontaneously hypertensive rats. Br J Pharmacol 133: 117-124.
11. Bucki R, Pastore JJ, Giraud F, Sulpice JC, Janmey PA (2003) Flavonoid inhibition of platelet procoagulant activity and phosphoinositide synthesis. J Thromb Haemost 1: 1820-1828.

12. Orsolić N, Knezević AH, Sver L, Terzić S, Basić I (2004) Immunomodulatory and antimetastatic action of propolis and related polyphenolic compounds. J Ethnopharmacol 94: 307-315.

13. Cushnie TP, Lamb AJ (2005) Antimicrobial activity of flavonoids. Int J Antimicrob Agents 26: 343-356.

14. Sharma P, Gujral HS (2010) Antioxidant and polyphenol oxidase activity of germinated barley and its milling fractions. Food Chem 120: 673-678.

15. Tian S, Nakamura K, Kayahara H (2004) Analysis of phenolic compounds in white rice, brown rice, and germinated brown rice. J Agric Food Chem 52: $4808-4813$.

16. Koyama M, Nakamura C, Nakamura K2(2013) Changes in phenols contents from buckwheat sprouts during growth stage. J Food Sci Technol 50: 86-93.

17. Zhang G, Xu Z, Gao Y, Huang X, Zou Y, et al. (2015) Effects of germination on the nutritional properties, phenolic profiles, and antioxidant activities of buckwheat. J Food Sci 80: H1111-1119.

18. Wang C-Y, Wu S-J, Shyu Y-T (2014) Antioxidant properties of certain cereals as affected by food-grade bacteria fermentation. J Biosci Bioeng 117: 449-456.

19. Poutanen K, Flander L, Katina K (2009) Sourdough and cereal fermentation in a nutritional perspective. Food Microbiol 26: 693-699.

20. Moroni AV, Zannini E, Sensidoni G, Arendt EK (2012) Exploitation of buckwheat sourdough for the production of wheat bread. Euro Food Res Technol 235: 659-668.

21. Chae MH, Jhon D-Y (2006) Preparation of kimchi containing bifidobacterim animalis DY-64. J Microbiol Biotechnol 16: 431-437.

22. Yoo J, Kim Y, Yoo S-H, Inglett GE, Lee S (2012) Reduction of rutin loss in buckwheat noodles and their physicochemical characterisation. Food Chem 132: 2107-2111.

23. Prior RL, Hoang H, Gu L, Wu X, Bacchiocca M, et al. (2003) Assays for hydrophilic and lipophilic antioxidant capacity (oxygen radical absorbance capacity (ORACFL)) of plasma and other biological and food samples. J Agric Food Chem 51: 3273-3279.

24. Steadman KJ, Burgoon MS, Lewis BA, Edwardson SE, Obendorf RL (2001) Minerals, phytic acid, tannin and rutin in buckwheat seed milling fractions. J Sci Food Agric 81: 1094-1100.

25. Vojtíšková P, Kmentová K, Kubán V, Kracmar S (2012) Chemical composition of buckwheat plant (Fagopyrum esculentum) and selected buckwheat products. J Microbiol Biotechnol Food Sci 1: 1011-1019.

26. Cho YJ, Bae IY, Inglett GE, Lee S (2014) Utilization of tartary buckwheat bran as a source of rutin and its effect on the rheological and antioxidant properties of wheat-based products. Indust Crops Products 61: 211-216.

27. Chlopicka J, Pasko P, Gorinstein S, Jedryas A, Zagrodzki P (2012) Total phenolic and total flavonoid content, antioxidant activity and sensory evaluation of pseudocereal breads. LWT-Food Sci Technol 46: 548-555.

28. Sun T, Ho C-T (2005) Antioxidant activities of buckwheat extracts. Food Chem 90: 743-749. 